Article

\title{
Spreading Sustainability Innovation through the Co-Evolution of Sustainable Business Models and Partnerships
}

\author{
Silvia Cantele *(i), Sara Moggi $@$ and Bettina Campedelli $®$ \\ Department of Business Administration, University of Verona, 37129 Verona, Italy; sara.moggi@univr.it (S.M.); \\ bettina.campedelli@univr.it (B.C.) \\ * Correspondence: silvia.cantele@univr.it
}

Received: 2 January 2020; Accepted: 3 February 2020; Published: 7 February 2020

check for updates

\begin{abstract}
Sustainability innovation is often not achievable by a single organisation; even if changes in business operations can lead to great advances towards a more sustainable business model (SBM), the effectiveness of these implementations largely depends on the combined actions of the organisation's network of partners. The aim of this research is to analyse the way that SBMs and partnerships co-evolve to enhance the sustainability of the involved organisations and spread sustainability culture beyond the network. In doing so, this article presents a case study of the company Alisea as a business operating within a circular business model, along with its network of partnerships. The co-evolution of the business model and partnerships is led by enabling factors that characterise the underlying relationships. The role of cross-sector collaborations is demonstrated in terms of boosting the social and environmental dimensions of the circular business model, enhancing social and economic benefits within and outside the partnerships, and spreading sustainability culture in different sectors.
\end{abstract}

Keywords: sustainable business model; sustainability innovation; cross-sector partnership; circular economy; network

\section{Introduction}

Concerns about sustainable development and the correct use of natural resources have led a transformation towards more sustainable processes of production and consumption [1]. To support this evolution, numerous businesses have begun embedding sustainability issues in their strategies and actions, although they rarely incorporate sustainability in each process and operation [2]. Sustainability has three dimensions (economic, social and environmental) that must be holistically implemented [3], yet most companies still work to develop only the environmentally friendly side of their production, without considering the whole picture of business effects [4]. To advance towards more sustainable production, further efforts should be based on innovation embracing sustainable technologies and processes [5,6]. A business model (BM) represents the way an organisation creates, delivers and captures value [7]. Although BMs usually list aspects that contribute to financial performance [8], other levers can support innovation, growth and sustainability [9-12]. This has led to the idea of the sustainable business model (SBM), in which actions towards sustainable development are embedded in the traditional BM through different SBM archetypes [13]. The recent literature underlines the importance of studying the BMs of organisations through a boundary-spanning perspective [14], by considering the relationships surrounding the focal organisation of a network and the organisations that collaborate with it $[15,16]$. This perspective can help shed light on the reciprocal positive influence among organisations from different industries or sectors, linked with each other by shared values and reciprocal collaboration 
based on sustainability innovation. Despite the evidence for this reciprocal influence, little is known about how this relationship could be enhanced and how cross-sector collaborations effectively influence the focal organisation's BM. The intersection of these fields of research has not been explored in depth yet. In particular, there are few studies on how sustainability innovation is transferred across the focal firm business model and its network of collaborations to potentially reach implementations in different industries and sectors, and what are the factors that enable this evolution and spread. Considering these research gaps, the present paper focuses on the following research questions:

- How can the SBM of the focal organisation and its network of partnerships co-evolve to spread sustainability innovation?

- What enabling factors enhance this type of collaboration and its evolution?

To achieve this, the case of Alisea Recycled and Reused Objects Design (from here Alisea) company was selected for examination because it represents a unique example of cross-sector and same-sector partnerships that have continuously evolved over time as the SBM of Alisea progressed. This company recycles and reuses waste to produce gadgets supplied in a business-to-business environment, and has enlarged its partnerships beyond the boundaries of the for-profit sector to spread its idea of sustainability innovation and to further develop its BM. The case study analysis followed a qualitative approach developed over one year of data collection and mainly based on semi-structured interviews and document analysis of a large number of materials also provided by the company. The analysis of these data was undertaken to identify the enabling factors of this collaborative circular BM, and to demonstrate the ways this model can spread across different industries and sectors.

In addition, the paper provides a picture of the possible interaction between the SBM of the focal organisation and the evolution of its network of collaborations. The Alisea case study indicates the way that an environmentally focused BM can include further social and economic aspects through its same-sector and cross-sector collaborations. The case highlights that, starting from shared values and visions, the development of partnerships enlarges the spectrum of value creation and creates virtuous circles that lay the foundation for further partnerships, sustainability innovation and BM development.

This paper is structured as follows. The first section provides the theoretical backgrounds of the three core concepts, presented in two subsections on issues regarding sustainable and innovative BMs, and collaborations and partnerships and their main features and drivers. The methodology section discusses the data collection and analysis, while the results are presented in subsections divided according to the three phases of Alisea's BM development. Finally, the discussion presents insights regarding the way SBMs can evolve with the network of same-sector and cross-sector partnerships, the enabling factors that favour this evolution, and the consequent spread of sustainability innovation in different contexts. The final reflections and limitations of the study are then provided, together with prospective contributions to literature and practice.

\section{Theoretical Background}

\subsection{Sustainable Business Model Innovation}

To achieve further sustainable and responsible production, more environmentally friendly innovations are needed [17,18] alongside sustainable supply chains [19] and new BMs that support sustainable business [5,6] and embed the three dimensions of sustainability (social, environmental and economic) [2]. Although there is no uniquely recognised definition of BM [20], it can be considered a reflection of 'how an organization creates and captures value, thereby describing the underlying logic of the organization' [2] (p. 4515). The employment of the BM concept is usually linked with the beginning of the dot-com period, which led to new methods of doing business [21]. A BM can be a tool to evaluate a company's value chain [5] and steer plans and innovative projects [22,23].

While BMs mainly list components that contribute to financial performance [8], other factors can support innovation, growth and sustainability [9-12]. From this view, the concept of the SBM has 
arisen as a BM that contributes to sustainability, while also providing a competitive advantage and higher customer value [24]. Although the SBM was initially a step towards including sustainability considerations in organisations' BMs [25-27], the SBM is increasingly becoming appreciated as a lever of competitive advantage [28,29]. According to [30], SBMs differ from the traditional BM concept in two main features: (i) embedding meanings, norms or aims related to sustainability, and (ii) incorporating sustainability into value proposition, value creation and related activities, and value capture mechanisms.

The literature on SBMs is vast and considers several nuances in its subcategories, archetypes or strategies for sustainability, such as product-service systems or circular BMs [13], and other areas where such BMs can be seen as important tools for change [24,31]. According to [30], SBMs 'are not only creating sustainable value, employing pro-active multi-stakeholder management, and have a long-term perspective, but also close, slow, intensify, dematerialise, and narrow resource loops' (p. 403) (see also [2,31-33]).

As noted by [13], to enhance SBMs and actions towards sustainable development, it is crucial to deeply innovate traditional BMs. This can be supported through a daring change to the dominant business logic that offers only profit-normative templates to create and capture value $[22,34,35]$. SBMs can also be the starting point for providing a novel combination of products and services to reach increasingly complex customer demand. This combination requires further steps towards innovative strategies, supported by interaction between the stakeholders of the value production system, with the aim of building competitive advantage based on the continuous search for environmentally and socio-ethically positive new solutions and innovation [24,36]. These new solutions often use ideas coming from outside the single firm, and therefore appear related to the open innovation concept [37-44], which creates opportunities for cross-fertilisation and enables the design of new business models, thanks to sustainability solutions conceived in different industries, sectors and organisations.

$\mathrm{BM}$ innovation can be considered the process of designing and implementation of novel and feasible BMs, which starts with business modelling' [45] (p. 4384); thus, this concept supports the increasing consideration of sustainability as a lever to enhance innovation towards generating a sustainable model for value creation $[2,13,46]$. Embedding sustainability as innovation in the BM also means analysing and planning the transformation from one BM to another [30], and increasing the organisation's resilience based on a sustainable competitive advantage [47]. As summarised by [30] (p. 406), the aim of BM innovation for sustainability is twofold: (i) to adopt solutions/innovations that foster sustainability 'in its value proposition, creation, and capture elements or its value-network', and (ii) to reduce negative effects on the environment and society to enable organisational resilience and prosperity. The goal of more sustainable production can be promoted by embedding innovation into the SBM [48]. In this sense, the enterprise goal of flourishing is supported by BM innovation that recognises the importance of external factors in its value proposition, such as society, the environment, the market and a range of stakeholders [8,45].

\subsection{The Firm and Its Network: Business and Cross-Sector Collaborations}

Previous studies have underlined that collaboration with different actors is crucial for a successful SBM $[5,49]$. To define the different sustainable organisations that can contribute to value creation and innovation, a boundary-spanning perspective on the BM can be employed, thereby enabling exploration of the links between the focal organisation and the external actors in its network $[7,15,16]$. In accordance with [2], this perspective can help shed light on the role played by the focal organisation in enhancing value creation in its network and in the broader environment and society.

The network level of analysis in collaborations has been less studied in the cross-sector [50] and business network literature [51], where the point of view is often that of the focal organisation. Partnerships and collaborations are the relevant intermediate objects of study, located between single organisations and society, and identified by means of an institutionalisation process communicatively co-constructed by partners and stakeholders also toward symbiotic SBMs [52,53]. Further, interaction 
between partners can restructure their BMs through collaboration or even determine the creation of a completely new BM [54]; to facilitate this interaction, the eco-innovation literature has underlined the crucial role of intermediaries in supporting firms in the innovation process [55]. SBM innovation can be leveraged through cross-sector collaboration, with the creation of ad-hoc SBM archetypes such as the marketing-focused SBM, regulative SBM, inclusive SBM and social investment SBM [56]. The network level of analysis is also useful to represent boundary-spanning value creation and transfer in SBMs [2], given that traditional component-based representations of BMs (such as Canvas) are unable to capture these factors. The deepening of the relationship between SBMs and partnership evolution appears to be a relevant stream of research that has previously only been noted by some contributions in the field of collaborative and network BMs [57-59].

While the collaborative and network BM literature is in its early stages, the literature on cross-sector partnerships has mainly focused on single cases of collaborations between a business and a public sector or non-profit organisation (NPO), aimed at specific initiatives [60]. Cross-sector collaborations are relationships that involve two or more sectors who work cooperatively to address societal issues [61]. A similar purpose is described for cross-sector partnerships [62], which aim to solve economic, social and environmental problems through collaboration [63]: here, the emphasis is particularly placed on addressing complex social issues that extend beyond organisational boundaries [64]. More generally, all cross-sector partnerships have the 'imperative to realize benefits for the wider community rather than for special interests' [65] (p. 752): for example, where the diffusion of large environmental technology systems is concerned, public-private partnerships are considered pivotal factors [66].

Studies on cross-sector partnerships have analysed the different stages encompassed by these relationships [67-69], which appear similar to those proposed in the literature on strategic alliances and partnerships $[70,71]$. The stages of 'formation', 'implementation' and 'outcome' can be conceptually identified, although the relationship is usually considered to evolve along a continuum lifecycle [72]. The positive evolution of the collaboration is influenced by certain factors that arise during specific stages. In the formation stage, typical antecedents are the presence of shared values among the partners [73] and the absence of opportunistic behaviours. During the implementation stage, trust and commitment are the determinants of positive relational effects, such as relationship learning and cooperation.

These critical success factors are similar to those already highlighted in the literature on strategic alliances and business collaborations. In [74], Christoffersen considered three groups of antecedents in strategic alliances, namely, behavioural attributes, dissimilarities and experience. Among behavioural attributes, commitment, trust and cooperation exert a positive impact on alliance success, while conflict could impact negatively; similarities between partners in terms of size, activities and organisational culture could enhance cooperation, and also a positive prior experience of alliances or prior knowledge between the partners could exert a positive impact [75]. In [76], Franco tested the impact of relations and compatibility, and interactions between partners and found these factors to significantly and positively impact on alliance success; relations and compatibility refer to trust, lack of opportunistic behaviour, good relationships, informal links and commitment; interactions between partners refer to joint decision-making and exchange of ideas and knowledge between participants. Many studies on inter-organisational networks highlighted that the success of these networks is based on relational governance [77-81] and social capital [82-84], which enable inter-organisational knowledge transfer [85,86].

Despite the increasing attention on cross-sector partnerships, little is still known about what happens when the firm is engaged in different kinds of partnerships across sectors at the same time, and how network collaborations and cross-sector partnerships can enhance the sustainability performance of the focal firm through sustainable business model evolution and spread sustainability innovation across different sectors and industries. 
The purpose of this research is to improve the knowledge on these emerging issues by considering how sustainability innovation is transferred across the focal firm business model and its network of collaborations and what are the factors that enable this evolution and spread.

\section{Methodology}

This research draws on the qualitative case study of Alisea- a firm located in the north of Italy, supplying gadgets and promotional objects created with recycled and reused materials. These products are not directly manufactured by Alisea but through its network of partners, which together present an innovative idea of a circular BM. This case was selected because it represents a unique example of same-sector and cross-sector collaborations that have continuously evolved over time alongside Alisea's BM. The boundaries of this case embrace Alisea and a number of its main partners, based on the company's situation in October 2018. As a result of Alisea's continuous search for sustainability innovation and new purposeful relationships, its partnerships are constantly increasing in terms of new business.

The case study approach followed in this work is a research strategy, which helped the comprehension of dynamics among actors in the particular context [87]. This exploratory qualitative approach is usually chosen to investigate unique examples and particular circumstances [88] through in-depth analysis of the case. Data collection was based on qualitative methods, including semi-structured interviews with the key informants in Alisea and its partners, such as material suppliers, subcontractors, costumers, non-profit and public sector organisations, and other partners. The people interviewed were selected based on the approach of chain (or snowball) sampling [89], starting with Alisea's chief executive officer (CEO), and involving entrepreneurs, CEOs and managers in charge of the relationships with Alisea (see Table 1). Alisea's CEO was interviewed four times with the aim of monitoring the evolution of Alisea's partnerships.

Table 1. Interviewees' roles and organisations.

\begin{tabular}{ccccc}
\hline Interview Code & Organisation & Sector & Interviewee Role & Interview Date \\
\hline A1 & Alisea & Business & Chief Executive Officer (CEO) & $20 / 10 / 17$ \\
A2 & Alisea & Business & CEO & $20 / 02 / 18$ \\
A3 & Alisea & Business & CEO & $19 / 06 / 18$ \\
A4 & Alisea & Business & President & $18 / 09 / 18$ \\
FP1 & Unisma Srl & Business & Operations manager & $22 / 03 / 18$ \\
NP1 & Cooperativa Sociale Agape & Non-profit & Ex-partner & $26 / 03 / 18$ \\
FP2 & Tecnostampi di Monteviale & Business & CEO & $12 / 03 / 18$ \\
FP3 & WRAD & Business & Non-Profit Organisation (NPO) relationship manager \\
FP4 & Banca Popolare di Milano & Business & Marketing manager & $18 / 04 / 18$ \\
FP5 & Buffetti SpA & Business & Chief financial officer & $23 / 04 / 18$ \\
FP6 & Tecno EDM Srl & Business & Research and development (R\&D) manager \\
FP7 & Panama Trimmings Srl & Business & Council member & $02 / 05 / 18$ \\
PS1 & Calabria Region & Public & President (and school teacher) & $05 / 10 / 18$ \\
NP2 & Associazione Culturale Archimedia & Non-profit & Mayor & $05 / 10 / 18$ \\
PS3 & Savignano sul Panaro Municipality & Public & President & $12 / 10 / 18$ \\
NP3 & Cooperativa Sociale Alice & Non-profit & & $11 / 10 / 18$ \\
\hline
\end{tabular}

Semi-structured interviews employ unstructured questions to enhance the dialogue among participants and increase the quality of the data collected in an exploratory study [89,90]. Interviews were conducted according to an interview guide organised into four main aspects: innovation toward sustainability drivers, BM in circular economy, partnerships and networks, and the role of Alisea in these partnerships. The interview framework was adapted according to the role of the key-informant inside the complex structure of the Alisea network. In summary, the purpose of each interview was to deepen our understanding of the nature of relationships established between Alisea and each partner, the process of diffusion of, and the critical factors in this process of transfer and SBM evolution.

In addition, supplementary materials were embedded into the hermeneutic unit to enhance data source triangulation and the rigour of the qualitative study [89]. These secondary materials were annual and non-financial reports, website press releases, internal reports on sustainability project development, YouTube videos and other media sources on Alisea projects and partnerships. The additional materials 
improved the understanding of the case study and its network context by also considering how Alisea communicated its collaborations for. The overlap of some of this information allowed us to confirm data collected by interviews and increased the knowledge on additional projects that Alisea is developing inside the network.

Data collection was undertaken between October 2017 and October 2018 and included a total of 16 semi-structured interviews. Verbal informed consent was ensured at the beginning of each interview. Following the research protocol, an interview guide was followed; however, the flow of discourse was respected through adopting a flexible approach in the semi-structured interviews. The interviews lasted from $45 \mathrm{~min}$ to two hours, and each interview was recorded and verbatim transcribed for data analysis. At the beginning of each interview, the aim and nature of the research were explained to each interviewee, underlining the importance of their opinion and perspective on the collaboration with Alisea and other organisations engaged in the circular economy.

Despite the research framework followed by the researchers during the interviews, the open-ended questions enhanced the interviewees' involvement in the discussion and covered all the issues of research interest [91]. These interviews provided several insights into the relationship between Alisea and its partners that were crucial for identifying the enabling factors and the influence of these relationships on Alisea's BM and collaborative network evolution.

Data analysis followed an inductive coding process informed by the aims of the research. Following [90], in the first coding phase the milestones of the Alisea SBM evolution were identified, then through an open coding, the enabling factors for this evolution were detected and then reduced for identifying the relevant categories (axial coding). Finally, selective coding was employed to summarise the enabling factors of the core aspects. The coding phase was undertaken separately by two researchers, and the results were then compared to reach common agreement regarding the different coding results [92].

\section{Results}

This section presents the evolution of Alisea's SBM abreast of the development of its network of partnerships considering three main periods as milestones of its business evolution. This evolution should not be viewed in strict terms, as the three businesses still coexist and reciprocally contribute to sustain the firm and its network of business and cross-sector collaborations.

\subsection{Alisea's Business Model and First Network Collaborations}

Alisea Recycled and Reused Objects Design is a firm located in North Italy, which supplies gadgets and promotional objects in a business-to-business environment. The company was founded in 1994 by Susanna Martucci, a female entrepreneur who created the business after 15 years of experience in the sales department of a large publishing group. The initial entrepreneur's idea was to consider environmental issues as a key lever of business because, as she underlined: 'The environmental theme was a speech already heard and it was taken for granted that waste will be a gold mine for the future. But this is not great news if you are not able to interpret it. We chose to follow this idea [by] moving the focus from the use of the product to the value it could represent' (A1).

To confront Chinese competition in the gadget market, Alisea decided to sell relatively cheap objects, yet with high quality and a green history, which would make them unique. They decided 'not to sell just pens, pencils, notebooks, but to sell the way in which those objects were made' (A1). Their other decision was to maintain production in Italy; however, to face the higher costs of production, the entrepreneur 'started asking the companies [with whom they] worked for what they threw away' (A1). In this manner, Alisea could start competing in a market monopolised by low-quality offers by responding with a strong emphasis on innovation and by creating design objects made with its customers' waste materials, which are costless yet offer unique products from the companies' own waste. This was the origin of a BM based on circular economy, which 'is basically an economy that 
feeds itself, where the inevitable production waste of one [company] becomes raw material for another' (A1).

Alisea's BM encompasses two types of circular processes: (i) upcycling of waste materials by using virgin materials (e.g., producing vases made of dried tomato peels and wax) and (ii) recycling, where waste materials are used in a new manufacturing process that leads to completely new products (e.g., producing pens made of plastic recycled from the lights of dismantled Volkswagen cars). The first important aspect of this BM is economic sustainability-the waste materials do not have to be purchased by Alisea, and the economic benefits can be shared within the supply chain. As a supplier underlined, it is necessary to 'have common goals that are economically valuable for everyone because otherwise collaborations do not make sense' (FP1). The second important aspect of Alisea's BM is the role of design and beauty. Waste materials are used to create well-designed and attractive objects; otherwise, 'they are not able to face the competition of new products in terms of appearance and quality' (A1). Similarly, a supplier stated:

We must meet what, in our opinion, is the development of the ecological sense of the people-that is, a sensitivity that people begin to have. But to get to this, you have to make products that are attractive because if the stuff is ugly, you will never sell it (FP1).

The third fundamental element of their innovative approach is that they do not propose just gadgets, but objects that 'communicate' to the customer: 'Unlike what happens in other recycling philosophies, we do not want the previous life of a material to disappear in a new project identity. The object of today's design maintains the memory of what it was in the past, because recycling is not a cheaper way to gain materials, but a creative stimulus that adds value to the project' (from the Alisea website).

The value of the objects is not in the material itself, but in the idea of using waste materials, the research needed to create beautiful objects from these materials, the professional design, and the implicit message of the sustainability that this production system allows.

The need to offer a large range of objects, based on different waste materials with different technologies, steered the firm to establish partnerships with a large number of manufacturing firms-mainly small firms based on artisan production. These firms' know-how built on years of experience embeds 'important information on the materials, on their melting points, on all [that] is needed for the transformation process' (A1). This led Alisea to gain a large number of contacts with local firms, with a consequent positive effect in terms of reputation by word-of-mouth. A growing number of potential customers were subsequently informed about the existence of Alisea and its special offer of design and sustainable, custom-made objects. Not all suppliers were willing to accept this intrusion into their factories; however, this led to a natural selection of businesses that were more eager to support a proactive, innovative and collaborative approach (see Figure 1).

The ability of Alisea to create a network of effective relationships was recognised by an interviewee, who underlined the pivotal role played by Alisea's entrepreneur as follows:

She is definitely the strongest element in the network, on the one hand for motivation and on the other hand for her very wide competence-not focused on a single product but starting from the problem or customer's requirement (FP4).

Through its continuous search for innovation, Alisea's business network attracted an increasing number of customers among large international organisations and brands, such as the World Wide Fund for Nature, New Holland and Volkswagen. According to Alisea's founder, Alisea's ideas were so innovative that they attracted high-level companies that were 'the first to be bored by the usual products and looking for a message of communication that goes beyond the moment, towards the future' (A1). All these different collaborative relationships contributed to increase the know-how of Alisea's staff, who quickly became able to support the suppliers in their material manufacturing experiments in a vast range of different production processes. In addition, the suppliers received benefits in terms of know-how because they could try alternative production processes based on materials with which they had not previously experimented. The enlightened entrepreneurs who 
agreed to cooperate with Alisea did not fear its competition, as they knew this was not a manufacturing company working in the same industry, and did not view Alisea as the 'enemy'. For the partners in the Alisea network, the sharing of knowledge is fundamental and new ideas are the starting point for further processes of innovation, given that:

All the projects and all the meetings lead to growth, and surely Alisea has opened a world [with] new possibilities that are not just related to a single project, but that sow seeds that then maybe will sprout later when the time will be ripe (FP5).

This idea of openness was further stressed by other partners, who asserted that 'it is nice to be copied or adapted to other contexts' (PS3) and 'a mental openness is necessary. There is a difference between people who think you are stealing their idea, and those who are not afraid of this, as we are' (FP2).

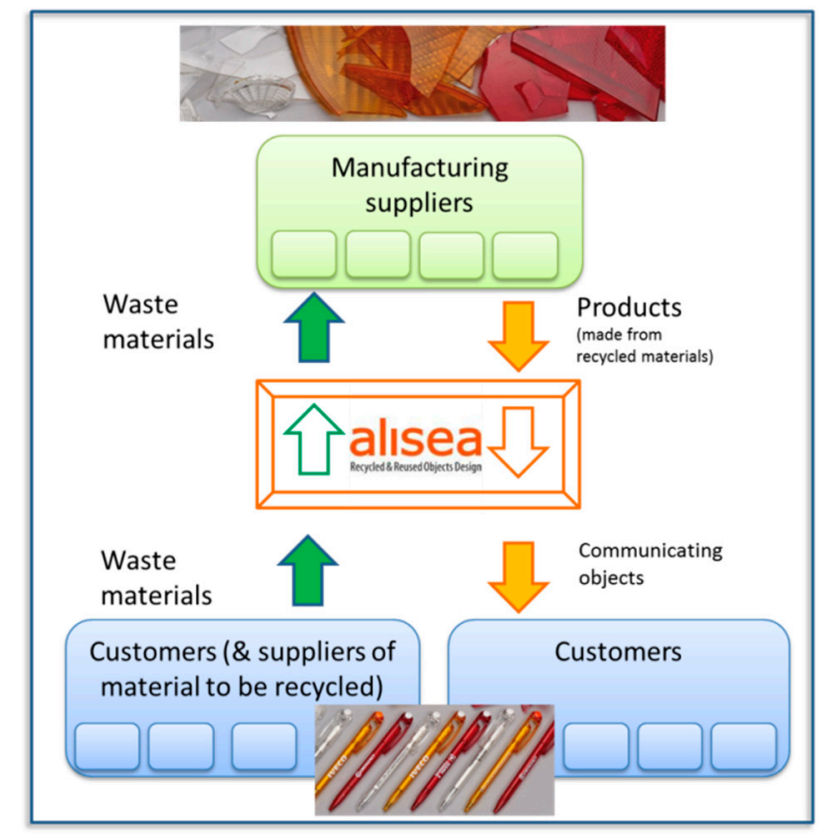

Figure 1. Alisea's first sustainable business model.

A project launched by Alisea's customer, Banca Popolare di Milano, provides an example of multi-party networking based on cooperation. This bank commissioned Alisea to produce a money box made by recycling plastic cups from the bank's canteen. This project enhanced the bank employees' responsibility regarding their environmental impact by involving them in the recycling process, and encompassed the catering company, the cup producer and the firms recycling the waste cups. Moreover, a further educational purpose was included, as the money boxes were donated to children at public events to support the idea of saving money from an early age, yet also with a strong environmental message.

Another important aspect of Alisea's BM is continuous curiosity and the search for new challenges to maintain the company's first-mover position:

We are always further ahead because we are always going forward [with] something that has never been done before. In front of a new challenge, someone [else] says, 'I don't know if it works', while we say 'Fantastic! Send it [the waste material] to us [and] we will see what we can do with it' (A1).

This approach is enabled by collaborating with suppliers that share the same vision, curiosity and need to continuously experiment with new productions through new processes of transformation: 'Our outcomes are the result of practices and processes coming from the belief that nothing is impossible. We have created products that, according to traditional manufacturing knowledge, could never have been done' (FP1).

The same enthusiasm, sense of networking and shared vision also characterise the cross-sector collaborations created in this phase of evolution of Alisea's SBM. The mayor of Savignano sul Panaro 
municipality was the creator of the 'Goodness Minerva' project, which was sponsored through Alisea gadgets and promoted by Alisea as an exemplar project among similar municipalities, as well at a higher policy level (environmental ministry's staff). The project is an educational project in which certain waste materials are collected at the local school by students and families and sold by the municipality to a social cooperative in the waste supply chain (rather than to the 'official' waste disposal utility). In this manner, the municipality reduces expenses for disposal services and earns funds entirely destined for the school. This project includes environmental benefits, educational purposes and fair economic gains for everybody engaged because 'everyone grows in an adequate manner and has space to give something to someone else' (PS3).

\subsection{The 'Perpetua' Revolution}

In 2012, Alisea created 'Perpetua' based on the request of a customer-a producer of electrodes-who asked the firm to design promotional objects with its graphite powder waste. Alisea's entrepreneur had the idea of creating a pencil yet learnt there were no producers of pencils in Italy. This inspired the idea to become the first Italian pencil manufacturer by offering a completely new product based on innovative design and technology. The name 'Perpetua' (eternal) was chosen as a tribute to the homonymous character of Alessandro Manzoni's novel, I Promessi Sposi (The Betrothed), and because it alludes to the long life of this pencil, compared with traditional pencils. Perpetua is a sustainable product because it does not use wood and is made with $80 \%$ recycled graphite and other non-toxic materials. With Perpetua, a new form of recycling was coined-'self-cycling'-because, by using a Perpetua pencil, each customer can consume $15 \mathrm{~g}$ of recycled graphite. Similar to other Alisea products, the pencil 'communicates', as it is always sold with a cardboard that tells its history and presents the values of the customers who use the custom-made pencils. As with other products, the pencil has been produced for famous companies and events, such as Star Wars, Arena, Audi, Fiat Chrysler Automobiles group and the Taormina G7 meeting.

The environmental aspects of the product are matched with economic sustainability: the use of recycled graphite contributes to reducing the cost of Perpetua, while the correspondent virgin raw materials would have been too expensive. Economic advantages are also gained by the electrode producer (Tecno EDM), which can reduce the disposal costs of its graphite powder. Initially, Tecno EDM was unconvinced about Alisea using the graphite powder, as firms often simply view their waste as waste, without the capability to think about alternative destinations. As stated by one interviewee:

I was thinking, what could she do with it [the graphite powder]? For us, it was only a cost to bear. So, I started with a negative feeling, but something fantastic has happened. She created a product which is now known everywhere and from that, a new world is born (FP6).

The research and development for the creation of the final product was the start of a relationship for which both firms expressed enthusiasm—-the 'rigid' mechanical industry met the creative world of design and communication objects, and started feeling the results acquired by Perpetua as its own results. This feeling was defined well by Alisea's partner: 'I am really proud of having helped Alisea and contributed to create a similar world' (FP6).

From the beginning, their relationship was based on transparency, reciprocity and respect for the privacy of reserved information. Trust was the basis of the collaboration in two senses. First, personal trust was determined by the value fit between the two firms:

We share the same values; there is no need to sign anything, unlike this world which does the opposite, as when someone elicits information from another [and] suddenly tries to walk all over him, to stab him in the back. This does not exist between us, she [Alisea's funder] swears by us and we too (FP6).

Second, trust was built on the capabilities and quality of the project: 'At the beginning, I was sceptical, but after, I thought "one never knows, you never know". I'll let her get on with it as she knows what to do' (FP6). This approach of working together strengthened the collaboration and reciprocal commitment: 'Alisea will always have support from me as there is this way of collaborating 
very honestly and transparently, without any doubts about the fairness and seriousness from both parts' (FP6).

The supply chain relationships with the suppliers and many customers of Perpetua (see Figure 2) were accompanied by cross-sector collaborations that arose as soon as the new BM of Alisea was implemented. In particular, two partnerships with NPOs (social cooperatives) were established in Perpetua's BM-the 'Agape' and 'Alice' social cooperatives. Agape is a local social enterprise that employs people with severe disabilities, which was appointed to complete all the packaging, shipping and e-commerce processes of Perpetua. Alice is a social cooperative that offers work to women serving a term of imprisonment. These women manufacture the pencil case (G-case) that completes the Perpetua product line. By means of these two partnerships, the environmental and economic dimensions of sustainability related to waste material use are supported with social and economic effects from Perpetua's BM. In particular, economic value is created and distributed for the services supplied by the cooperatives (who are paid at market prices, regardless of their social nature), and social value is created because Perpetua contributes to the aim of these partner cooperatives to offer work to disadvantaged people.

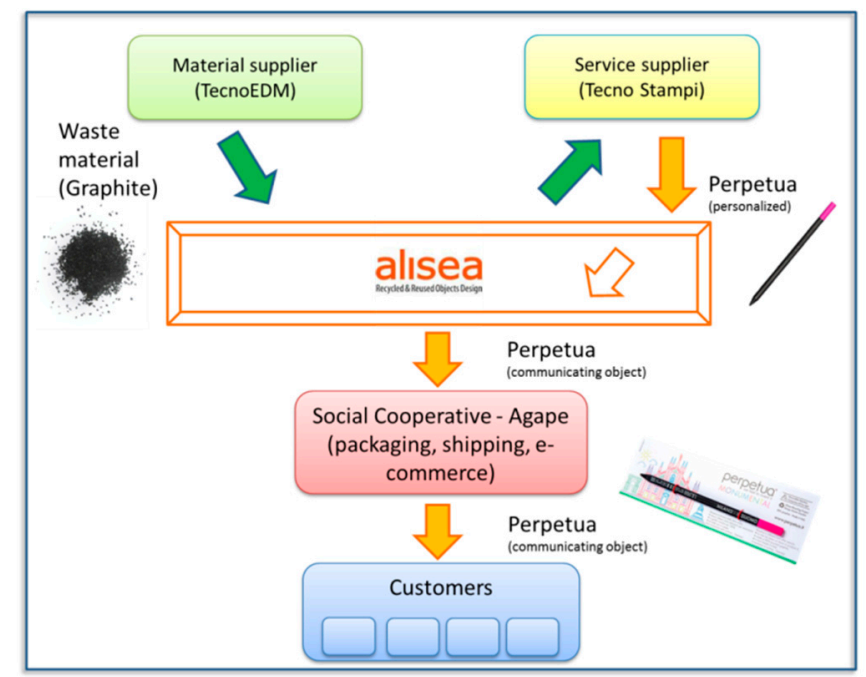

Figure 2. Alisea's second sustainable business model (Perpetua business model).

The relevance of Perpetua sharing the common social mission of Agape is clear, as Alisea's entrepreneur uses any opportunity to discuss this partnership in order to offer Agape visibility and thus the possibility to receive further work and support from other companies. This was illustrated by an Agape interviewee: 'She gave us the possibility to be known around; it is a good way to be acknowledged and communicate what we created together' (NP1). The basis of the relationship is sharing common values and trust: 'It is very rewarding finding firms to work with this sensitivity created over time; clearly, this means that there is a relationship based on trust, confidence and sharing of a certain kind of principles' (NP1). In addition, a certain reciprocal acknowledgement is recognisable, as Perpetua chose Agape for its commitment to offering work to people with all forms of disability (including the most serious), while Agape recognises a sincere social commitment, whereas other firms can take advantage of the status of social cooperatives by paying non-equitable prices for their services.

The synergy created with the Alice social cooperative is also highlighted because the relationship is not limited to the main common project, called 'Socially Made in Italy'. In fact, as expressed by the president of Alice, 'the synergy created cannot be measured based on the operations we put into practice. If we should base [it] on that, this would be very little compared to what is behind' (NP3). The commercial relationship appears to be only the starting point of a 'dialogue space', based on a 'common matrix', where 'there is a total sharing, each success for us or them is a common emotion, we are the same family by now and we travel with the same purpose' (NP3). This sense of sharing 
common goals is considered a precondition of any sustainability project: 'We need to join forces, as I am convinced that sustainability is such a hybrid matter that it is in the specific competences of nobody-rather, it is the sum of all, it is a logic of transversality' (NP3). Moreover, as a reciprocal acknowledgement of a similar vision, the relationship is considered a way to do 'critical mass' and 'good lobby', in contrast to those 'people that at the conference desk speak and speak with no title and do a lot of self-referencing without the right incentive to found new solutions' (NP3).

As already evidenced with Agape, the link between Perpetua and Alice is a system of shared relationships, where each relationship acts in turn as a facilitator in the search for further partners for their respective activities. However, the relationships with NPOs are not limited to the supply chain, as the message of sustainability brought by Perpetua can inspire a new environmental culture, particularly among young people. This is why the social mission of Perpetua is supported through developing school projects aiming at environmental and cultural education. In collaboration with the cultural association Archimedia, Perpetua became a puppet in a theatrical show teaching students its sustainable story. As underlined by the president of Archimedia (and teacher in the participating school):

The aim is to teach to students and teachers the importance of taking care of the environment, without rhetoric, but instead with concrete actions. What is behind the Perpetua philosophy, what emerges about it from the web, the social networks and the press is real-there is the real will to save the planet (NP2).

The idea of creating a theatrical show and some laboratories dedicated to pupils was successful, and this project has been re-proposed to use in other schools in different geographical contexts. Moreover, Alisea and Perpetua are used as case studies of the circular economy at universities and professional associations' seminars.

\subsection{Endorsed by Perpetua: The Rise of Symbiotic Collaborations}

The natural openness of Alisea has operated as a catalyst for innovators who wish to create alternative businesses in the name of sustainability. The first important collaboration in this sense was with Matteo Ward-a young employee in the fashion industry, who, after working for a few years in the second-largest polluting industry in the world, decided to create a movement and a sustainable fashion brand (WRAD).

This cooperation led to the registration by Alisea of a new technology—the G_PWDR by Perpetua, which uses recycled graphite to paint clothes. Moreover, it led to the launch of Graphi-Tee- - the first organic cotton T-shirt that uses this type of technology. The G_PWDR process aims to save waste, energy and water by reducing the clothes production phases from four to two. The partnership between Alisea and WRAD comprises not only formal support but also the use of plants, offices and knowledge accumulated during years of experience in the use of recycled graphite: 'They give us all their resources, all their know-how on graphite and related to Perpetua production, allowing us to translate their experience into the textile world' (FP3).

From this partnership, the idea of 'endorsed by Perpetua' was derived-a brand created, and recorded as a patent, to identify the products of firms that share the values, attitude and vision of Perpetua. An 'endorsed by Perpetua' product allows firms in several business sectors to develop products and new ideas by using the knowledge, communication skills, know-how, technologies and manufacturing processes of Perpetua (see Figure 3). The common view among partners was summarised well by the following participant: 


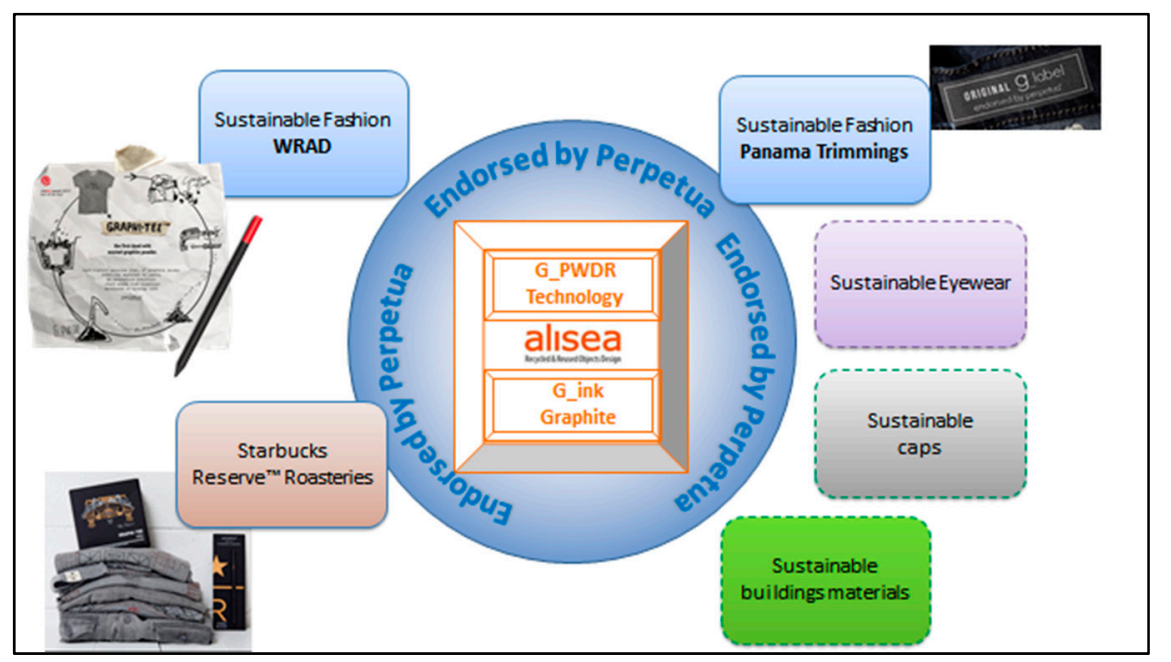

Figure 3. Alisea's third sustainable business model ('endorsed by Perpetua' business model).

Perpetua is not a pencil, rather a philosophy, and [our partners] have created a movement, not just a brand, because we have in common the same passion, same desire to change the world and very high skills already demonstrated (A1).

According to the Perpetua website, through 'endorsed by Perpetua', 'the change of manufacturing systems towards a deeper and conscious respect for the environment, the planet and the people living in it is enabled and sped up' (from the Perpetua website). The choice of Alisea was driven by the vision of a revolutionary idea that could offer advantages to both partners in a win-win situation. As noted by Alisea's entrepreneur, 'this is the concept of "endorsed by Perpetua", which speaks about symbiotic economy - that is, how the symbiosis between two companies gives rise to growth and energy that helps each other to face the global market' (A1). Given that the Graphi-Tee is an 'endorsed by Perpetua' product, it follows the win-win logic. In fact, the high communication potential of WRAD is bringing to Perpetua a renewed wave of popularity and opening the doors to new sales and advertising channels: 'The growth of WRAD favours the growth of Perpetua too, because we bring Perpetua to worlds where a pencil would never have arrived, such as YOOX Net-a-Porter' (FP3).

Another example of 'endorsed by Perpetua' is the collaboration with Panama Trimmings and their G-Label - a clothes label painted using graphite, using the know-how provided by Alisea. The clothes present their story of sustainability through a hyperlink on the G-Label website that presents their philosophy and the meaning of the endorsement from Perpetua. According to this logic:

The more Perpetua will be famous, the more one will go onto their website, giving visibility also to our products. Vice versa, someone who maybe would never go looking for a pencil could browse our G-Label and find Perpetua. This is free advertising (FP7).

The research and development necessary to produce the Graphi-Tee led WRAD and Alisea to develop a relationship with two organisations from the public sector. When seeking the best technology to paint clothes with graphite, they discovered that this was a practice well-developed by the Ancient Romans at the Monterosso Calabro Mines in the Calabria region (South Italy). These mines were maintained in operation until the last century, and this process was present as traditional informal knowledge among older women in the village. From this contact with WRAD and Perpetua, the municipality of Monterosso Calabro determined the economic potential of using the Roman mine as a tourist attraction, which has led their eco-friendly textile tradition to be featured on television documentaries. Moreover, the most important popularity effect gained by Monterosso from WRAD and Alisea's relationship has been the winning of the 'Handprint Award 2018' at the Green Carpet Fashion Awards in Milan, based on 'having maintained the memory of an ancient practice of dyeing fabrics with graphite powder coming from a local mine and used for centuries before being superseded by synthetic dyeing'. The relationship between Monterosso, WRAD and Perpetua has led the Calabria region to 
create two grant proposals: (i) to support the rediscovery of ancient villages, such as Monterosso, and (ii) to support young people who wish to stay in these villages and develop economic activity. Similarly to what Alisea had already found in other relationships, the link between Alisea and the Calabria region was summarised by one interviewee: 'What we search for is to create new relationships: to put into motion a network system' (PS1).

After WRAD and Panama Trimmings, other partnerships have started to progress and involve the ideas of spreading knowledge, technologies and sustainability values in different industries, such as the eyewear, construction materials and plastic products industries. Supporting the 'endorsed by Perpetua' projects means proposing a different lifestyle. This was particularly highlighted in the most recent collaboration between WRAD, Perpetua and Starbucks Reserve Roasters worldwide, where customised limited-edition items from Perpetua and Graphi-Tee were presented as 'tangible expressions of intangible values in harmony with the needs of our Planet and of the people living in it' and 'a "style of doing" that has found full affinity with ethics sustainable behaviour choices undertaken by Starbucks' (from the Perpetua website).

As summarised in Figure 3, the 'endorsed by Perpetua' BM is dynamic in nature and continuously seeking "contamination" as new opportunities for sustainability innovation: 'Now we are looking for new suppliers to bring us to new industries to find new ideas but always maintaining our values' (A3). Perpetua is becoming an 'incubator, an accelerator for those realities with the same [Perpetua's] DNA that want to exploit the R\&D of Perpetua, in the field of reuse of graphite. For Perpetua, this is positive because it increases the uses of its brand and brings Perpetua to other fields where it was not before' (FP3).

Moreover, as discussed above, the Perpetua and 'endorsed by Perpetua' projects are also used to spread the culture of sustainability innovation outside the business context, such as in schools, NPOs, and municipalities.

\section{Discussion}

The presentation of the Alisea case has highlighted the evolution of the SBM of the focal organisation across three main stages: Alisea and its first partnerships, the Perpetua revolution, and 'endorsed by Perpetua'. This evolution should not be viewed in strict terms, as the three businesses still coexist and reciprocally contribute to sustain the firm and its network of business and cross-sector collaborations.

The first SBM configuration, which we call 'Alisea' based on the name of the organisation, sees the firm as a focal point in a series of different supply chain relationships, created to deliver different products to different customers by using different waste materials and production processes. During this first stage, Alisea acquired diversified knowledge from both customers and suppliers [85] and became an expert in recycling waste materials to create a large array of promotional objects. The second specific element of this stage was the creation of an extended network of relationships [5,49], which, combined with growing knowledge, created the basis for the second configuration of the Perpetua SBM.

In the Perpetua SBM, the familiarity with recycling and the consolidated innovation propensity led the firm to invest in plants and delegate the production process to a contractor in order to offer on the market a completely new product (Perpetua). Perpetua is a patented process and a well-known international brand, used by large multinational and authoritative public and non-profit institutions. According to [30], the success of this SBM depends on a mix of favourable factors developed during its evolution such as the extreme innovativeness and sustainability of the products, and the communicative power of the brand, which is highly recognisable even though each customer has the possibility to customise and match the Perpetua product to its own brand [24,36]. The fame of this product gave a further boost to Alisea's network of relationships by spanning its BM boundaries $[15,16]$ to co-create further innovation in different industries and to spread the knowledge on sustainable growth and the diffusion of relative projects in cross-sector contexts.

The 'endorsed by Perpetua' SBM incorporated this further development, as the spread of the Perpetua philosophy among different industries and sectors demonstrated the potentially infinite 
opportunities delivered by a strong message of sustainability, incorporated in a vast assortment of products and projects, and enabled by a diversified network of same-sector and cross-sector collaborations. In fact, the different partnerships that have arisen are based on a common sense of belonging, and are sustained by the acknowledgement of a broader network of relationships and by the awareness that every project is not an end in itself but a first step towards a greater shared purpose - the idea of contributing to 'changing the world' and working for the common good [2,31].

The multiple-supply chain BM of Alisea and the revolutionary value proposition of the Perpetua BM make way for a constellation of new BMs, in which partners co-create new products based on the innovative materials or processes already experimented with by the firm. Similarly to what was underlined in [5], this situation has created a sort of 'restitution' of the growth enjoyed by the firm, thanks to knowledge sharing and relationship creation experienced in the former two BM evolution steps. This restitution offers a win-win situation, as Perpetua endorses the different projects yet also gains further development from them in a virtuous circle of synergistic value creation $[7,16]$ and formation of symbiotic SBMs [52,53]. The described evolution of Alisea through the three BMs appears to be the product of multiple interactions created within business-to-business and cross-sector collaborations.

The role of cross-sector collaborations has manifested in two main directions: the integration of further economic and social dimensions in the mainly environmentally focused BM of Alisea, and the broader extension of the network of relationships and beneficiaries of sustainability projects stemming from the Alisea and Perpetua BMs. Cross-sector collaborations have enlarged the scope of the sustainability initiatives of Alisea, giving depth and width in terms of the dimensions involved and effects [2]. Alisea and Perpetua represent two examples of circular BMs in which the environmental dimension is more developed than the economic and social dimensions. The benefits mainly arise from the reduction of waste material disposal (environmental positive effect) and from economic benefits delivered exclusively to supply chain partners-customers do not pay for the recycled materials incorporated in their promotional objects, material suppliers can reduce disposal costs, and manufacturing contractors receive extra work from external contracts led by Alisea. The collaborations with public administrations and NPOs, in turn, add social value to Alisea's and Perpetua's circular BMs and contribute to extend the economic value creation even towards people outside the formal network of collaborations.

Although case study analysis cannot provide generalised results, the present study unveiled some preconditions and enabling factors for the evolution of SBMs within a collaborative network that can be developed and enhanced in similar contexts. These antecedents of collaboration evolution and success somewhat correspond with those already highlighted in the literature on alliances $[74,76]$ and cross-sector partnerships [73], yet also present some peculiarities and novel aspects. According to the results, the following factors could be considered as essential elements for the development of a successful and resilient SBM in a collaborative network: (a) shared values; (b) absence of opportunistic behaviour; (c) sharing of knowledge; (d) trust (relatedness and belonging); (e) commitment.

The shared values found among the network of collaborations stem from the personal sensitivity of the individuals engaged in the projects [73]. All the interviewees spoke about their deep propensity for recycling, sustainability and environmental respect. This idea of sustainability was further defined in terms of beauty, creativity and design, and this seems to be the most relevant success factor in the proposal of circular economy products based on waste materials.

Another relevant aspect is the absence of opportunistic behaviour. The interviewees frequently discussed maximum transparency in sharing information, without fear of competition, so that each stakeholder can learn from the relationship. In Alisea's case, the idea of sharing of knowledge was particularly emphasised, as different partners explicitly referred to the will to be copied in their sustainability innovation ideas [12]. In fact, the possibility to contaminate different industries and sector contexts with these ideas appears to be the basis of the development and success of this network of partnerships. This extreme sense of openness is led by trust, as people involved in the partnerships and collaborations have profound esteem for Alisea's entrepreneur, who is recognised as the charismatic 
leader in the network. This trust is based on the idea of some type of relatedness in the personality of the partners-often referred to in terms of 'having the same DNA' or 'being on the same wavelength' in a common sense of belonging. In addition to this traditional interpretation of trust [76], the analysis highlighted an additional meaning of trust in the quality of the projects in which the partners were involved - the idea that all projects would succeed, even when they encountered technical difficulties or had never previously been successful.

The implicit belief in these similarities among people and the optimistic view of the projects' success creates a common sense of commitment towards the collaboration that is perceived as relevant for all parties engaged in common purposes [61]. The partnerships are based on the starting principle that the objectives should be economically valid for all-a win-win prerequisite, whereby all organisations involved should receive equitable benefit, regardless of whether they are a business, public organisation or NPO. Moreover, behind the economic dimension, all parties are focused on their shared higher social and environmental mission. This gives a larger perspective on the relationships and projects, the perception of further possibilities for development: the single projects in which the partners are involved often appear to be a starting point for further collaborations, in a type of 'ideas explosion'.

Moreover, further ideas are not the only basis for future development, as the real foundation is the informal network of relationships created around Alisea as the focal organisation. Alisea's natural openness in sharing knowledge, relationships and contacts has transformed its different partnerships into a real network of collaboration. This network perspective has emerged as a crucial antecedent in, as the results underline that, in a network, the total knowledge created is higher than the sum of the single partners' competencies, and some sustainability projects could never have been imagined without this sharing of ideas and trust in the worth of the partnerships.

\section{Conclusions}

This article has presented case study research of a firm and its network of collaborations in implementing circular BMs and spreading sustainability innovation in different business and non-business contexts. The case study organisation, Alisea, has experienced three evolutions in its SBM because of its own strategic decisions and because of collaborations and relationships created with different types of organisations.

The case presented the co-evolution of the firm's SBM and its business and cross-sector collaborations. The first Alisea SBM was strongly based on business relationships within the supply chain, while the subsequent Perpetua and 'endorsed by Perpetua' SBM evolutions were strongly characterised by the engagement of non-profit and public sector organisations. These relationships extended the environmental and economic dimensions of Alisea's circular BM towards having deeper effects on the social dimensions of the partnership, while also creating economic and social benefits for organisations and individuals outside the formal network of collaborations. The spread of sustainable culture, education and innovation subsequently led to new business opportunities for Alisea and its partners in a sort of virtuous circle.

This paper contributes to the literature on SBMs, business and cross-sector partnerships by expressing the reciprocal influences on their respective paths of evolution, and by proposing a focus at the network level of analysis instead of the most frequently used single-organisation and single-partnership levels. Another contribution refers to the antecedents or enabling factors of these types of collaboration, which present some novel aspects, such as the extreme openness to sharing knowledge, the continuous search for new challenges, and the idea that a single project shared with a partner is only the start of an indefinite series of opportunities based on the network of relationships that supports the project. Further, our analysis highlighted that these enabling factors are not different in business-to-business relationships and cross-sector relationships, as often emerged from the interviewees referring to common aspects. From the managerial perspective, the case study presents some specific drivers that can lead managers to create relationships that are beneficial to the firm's SBMs yet also contribute to 
a higher sustainable development mission. Thus, Alisea is an exemplar case study of cross-sector and multi-industry spread functional in the spread of sustainability innovation.

The limitations of our research reside mainly in having explored a single case study, even though this study referred to a network of collaborations and subsequently engaged different people and perspectives. Moreover, the data collection and analysis were undertaken over a one-year period, although the interviewees discussed experiences over decades of the firms' lives. Further research could study the continuous evolution of the case by means of a longer and real-time longitudinal analysis and by also considering a deeper analysis on value creation, delivery and capture across the BM evolution and within the network of symbiotic collaborations.

Author Contributions: Conceptualization, S.C.; methodology, S.M.; formal analysis, S.C.; investigation, S.C. and S.M.; writing-original draft preparation, S.C. and S.M.; supervision, B.C.; All authors have read and agreed to the published version of the manuscript.

Funding: This research is part of the project \#BIT Business Innovation \& Digital Transformation @ Vicenza, WP3 "Sustainable Business Models", funded by Fondazione Studi Universitari di Vicenza.

Conflicts of Interest: The authors declare no conflict of interest.

\section{References}

1. Roy, V.; Singh, S. Mapping the business focus in sustainable production and consumption literature: Review and research framework. J. Clean. Prod. 2017, 150, 224-236. [CrossRef]

2. Brehmer, M.; Podoynitsyna, K.; Langerak, F. Sustainable business models as boundary-spanning systems of value transfers. J. Clean. Prod. 2018, 172, 4514-4531. [CrossRef]

3. Elkington, J. Cannibals with Forks: The Triple Bottom Line of 21st Century Business; Capstone Publishing Ltd.: Oxford, UK, 1997.

4. Lozano, R. A holistic perspective on corporate sustainability drivers. Corp. Soc. Resp. Environ. Man. 2015, 22, 32-44. [CrossRef]

5. Boons, F.; Lüdeke-Freund, F. Business models for sustainable innovation: State-of-the-art and steps towards a research agenda. J. Clean. Prod. 2013, 45, 9-19. [CrossRef]

6. Lewandowski, M. Designing the business models for circular economy-Towards the conceptual framework. Sustainability 2016, 8, 43. [CrossRef]

7. Zott, C.; Amit, R. Business model design and the performance of entrepreneurial firms. Organ. Sci. 2007, 18, 181-199. [CrossRef]

8. Upward, A.; Jones, P.H. An ontology for strongly sustainable business models: Defining an enterprise framework compatible with natural and social science. Org. Environ. 2016, 29, 97-123. [CrossRef]

9. Campbell, D.; Danilovic, M.; Halila, F.; Hoveskog, M. The clash of BMs in emerging economies: The case of wind energy industry in Africa. Int. J. Manag. Sci. Inf. Technol. 2013, 9, 10-51.

10. Chesbrough, H. Business model innovation: Opportunities and barriers. Long Range Plan. 2010, 43, 354-363. [CrossRef]

11. Lambert, S.; Davidson, R. Applications of the business model in studies of enterprise success, innovation and classification: An analysis of empirical research from 1996 to 2010. Eur. Manag. J. 2010, 31, 668-681. [CrossRef]

12. Teece, D. Business models, business strategy and innovation. Long Range Plan. 2010, 43, 172-194. [CrossRef]

13. Bocken, N.M.P.; Short, S.W.; Rana, P.; Evans, S. A literature and practice review to develop sustainable business model archetypes. J. Clean. Prod. 2014, 65, 42-56. [CrossRef]

14. Laasch, O. Beyond the purely commercial business model: Organizational value logics and the heterogeneity of sustainability business models. Long Range Plan. 2018, 51, 158-183. [CrossRef]

15. Zott, C.; Amit, R. The fit between product market strategy and business model: Implications for firm performance. Strateg. Manag. J. 2008, 29, 1-26. [CrossRef]

16. Zott, C.; Amit, R.; Massa, L. The business model: Recent developments and future research. J. Manag. 2011, 37, 1019-1042.

17. Cosenz, F.; Noto, G. A dynamic business modelling approach to design and experiment new business venture strategies. Long Range Plan. 2018, 51, 127-140. [CrossRef] 
18. De Medeiros, J.F.; Ribeiro, J.L.D.; Cortimiglia, M.N. Success factors for environmentally sustainable product innovation: A systematic literature review. J. Clean. Prod. 2014, 65, 76-86. [CrossRef]

19. Linton, J.D.; Klassen, R.; Jayaraman, V. Sustainable supply chains: An introduction. J. Oper. Manag. 2007, 25, 1075-1082. [CrossRef]

20. Foss, N.J.; Saebi, T. Business models and business model innovation: Between wicked and paradigmatic problems. Long Range Plan. 2018, 51, 9-21. [CrossRef]

21. Nielsen, C.; Lund, M. A brief history of the business model concept. In The Basics of Business Models; Nielsen, C., Lund, M., Eds.; BookBoon.com/Ventus Publishing Aps: Copenhagen, Denmark, 2014; Volume 1, pp. 22-28.

22. Karlsson, N.P.; Hoveskog, M.; Halila, F.; Mattsson, M. Early phases of the business model innovation process for sustainability: Addressing the status quo of a Swedish biogas-producing farm cooperative. J. Clean. Prod. 2018, 172, 2759-2772. [CrossRef]

23. Magretta, J. Why business models matter. Harv. Bus. Rev. 2002, 80, 86-92. [PubMed]

24. Sousa-Zomer, T.T.; Miguel, P.A.C. Sustainable business models as an innovation strategy in the water sector: An empirical investigation of a sustainable product-service system. J. Clean. Prod. 2018, 171, 119-129. [CrossRef]

25. Rashid, A.; Asif, F.M.A.; Krajnik, P.; Nicolescu, C.M. Resource conservative manufacturing: An essential change in business and technology paradigm for sustainable manufacturing. J. Clean. Prod. 2013, 57, 166-177. [CrossRef]

26. Stubbs, W.; Cocklin, C. Conceptualizing a sustainability business model. Org. Environ. 2008, 21, $103-127$. [CrossRef]

27. Wells, P.E. Business Models for Sustainability; Edward Elgar: Cheltenham, UK, 2013.

28. Nidumolu, R.; Prahalad, C.K.; Rangaswami, M.R. Why sustainability is now the key driver of innovation. Harv. Bus. Rev. 2009, 87, 56-64.

29. Porter, M.E.; Kramer, M.R. Creating shared value. Harv. Bus. Rev. 2011, 89, 62-77.

30. Geissdoerfer, M.; Morioka, S.N.; de Carvalho, M.M.; Evans, S. Business models and supply chains for the circular economy. J. Clean. Prod. 2018, 190, 712-721. [CrossRef]

31. Bocken, N.M.P.; Short, S.W. Towards a sufficiency-driven business model: Experiences and opportunities. Environ. Innov. Soc. Transit. 2016, 18, 41-61. [CrossRef]

32. Ritala, P.; Huotari, P.; Bocken, N.; Albareda, L.; Puumalainen, K. Sustainable business model adoption among S\&P 500 firms: A longitudinal content analysis study. J. Clean. Prod. 2018, 170, 216-226.

33. Linder, M.; Williander, M. Circular business model innovation: Inherent uncertainties. Bus. Strateg. Environ. 2017, 26, 182-196. [CrossRef]

34. Hellström, M.; Tsvetkova, A.; Gustafsson, M.; Wikström, K. Collaboration mechanisms for business models in distributed energy ecosystems. J. Clean. Prod. 2015, 102, 226-236. [CrossRef]

35. Schaltegger, S.; Lüdeke-Freund, F.; Hansen, E. Business cases for sustainability: The role of business model innovation for corporate sustainability. Int. J. Innovat. Sustain. Dev. 2012, 6, 95-119. [CrossRef]

36. Vezzoli, C.; Ceschin, F.; Diehl, J.C.; Kohtala, C. New design challenges to widely implement 'sustainable product-service systems'. J. Clean. Prod. 2015, 97, 1-12. [CrossRef]

37. Bigliardi, B.; Galati, F. An open innovation model for SMEs. In Researching Open Innovation in SMEs; Frattini, F., Usman, M., Roijakkers, N., Vanhaverbeke, W., Eds.; World Scientific Publishing: Singapore, 2018; pp. 71-113.

38. Bogers, M.; Chesbrough, H.; Moedas, C. Open innovation: Research, practices, and policies. Calif. Manag. Rev. 2018, 60, 5-16. [CrossRef]

39. Cassiman, B.; Valentini, G. Open innovation: Are inbound and outbound knowledge flows really complementary? Strat. Man. J. 2016, 37, 1034-1046. [CrossRef]

40. Chesbrough, H.; Vanhaverbeke, W.; West, J. (Eds.) Open Innovation: Researching a New Paradigm; Oxford University Press: Oxford, UK, 2006.

41. Dahlander, L.; Gann, D.M. How open is innovation? Res. Pol. 2010, 39, 699-709. [CrossRef]

42. Enkel, E.; Gassmann, O.; Chesbrough, H. Open R\&D and open innovation: Exploring the phenomenon. RED Man. 2009, 39, 311-316.

43. Lopez-Vega, H.; Tell, F.; Vanhaverbeke, W. Where and how to search? Search paths in open innovation. Res. Pol. 2016, 45, 125-136. [CrossRef] 
44. West, J.; Bogers, M. Open innovation: Current status and research opportunities. Innovation 2017, 19, 43-50. [CrossRef]

45. Hoveskog, M.; Halila, F.; Mattsson, M.; Upward, A.; Karlsson, N. Education for sustainable development: Business modelling for flourishing. J. Clean. Prod. 2018, 172, 4383-4396. [CrossRef]

46. Pedersen, E.R.G.; Gwozdz, W.; Hvass, K.K. Exploring the relationship between business model innovation, corporate sustainability, and organisational values within the fashion industry. J. Bus. Ethics 2018, 149, 267-284. [CrossRef]

47. Mitchell, D.W.; Coles, C.B. Business model innovation breakthrough moves. J. Bus. Strateg. 2004, 25, $16-26$. [CrossRef]

48. Dyllick, T.; Muff, K. Clarifying the meaning of sustainable business introducing a typology from business-as-usual to true business sustainability. Org. Environ. 2016, 29, 156-174. [CrossRef]

49. Fadeeva, Z. Promise of sustainability collaboration-Potential fulfilled? J. Clean. Prod. 2005, 13, 165-174. [CrossRef]

50. Austin, J.E.; Seitanidi, M.M. Collaborative value creation: A review of partnering between nonprofits and businesses: Part 2-Partnership processes and outcomes. Nonprofit Volunt. Sect. Q. 2012, 41, 929-968. [CrossRef]

51. Provan, K.G.; Fish, A.; Sydow, J. Interorganizational networks at the network level: A review of the empirical literature on whole networks. J. Manag. 2007, 33, 479-516. [CrossRef]

52. Shumate, M.; Hsieh, Y.P.; O'Connor, A. A nonprofit perspective on business-nonprofit partnerships: Extending the symbiotic sustainability model. Bus. Soc. 2018, 57, 1337-1373. [CrossRef]

53. Shumate, M.; O'Connor, A. The symbiotic sustainability model: Conceptualizing NGO-corporate alliance communication. J. Commun. 2010, 60, 577-609. [CrossRef]

54. Dahan, N.M.; Doh, J.P.; Oetzel, J.; Yaziji, M. Corporate-NGO collaboration: Co-creating new business models for developing markets. Long Range Plan. 2010, 43, 326-342. [CrossRef]

55. Kanda, W.; Hjelm, O.; Clausen, J.; Bienkowska, D. Roles of intermediaries in supporting eco-innovation. J. Clean. Prod. 2018, 205, 1006-1016. [CrossRef]

56. Aagaard, A.; Lodsgård, L. Leveraging sustainable business model innovation through business-NGO collaboration. In Sustainable Business Models Innovation, Implementation and Success; Aagaard, A., Ed.; Palgrave-Macmillan: Basingstoke, UK, 2019; pp. 211-238.

57. Breuer, H.; Lüdeke-Freund, F. Values-based network and business model innovation. Int. J. Innov. Manag. 2017, 21, 1-35. [CrossRef]

58. Lindgren, P.; Taran, Y.; Boer, H. From single firm to network-based business model innovation. Int. J. Entrepr. Innov. Manag. 2010, 12, 122. [CrossRef]

59. Rohrbeck, R.; Konnertz, L.; Knab, S. Collaborative business modelling for systemic and sustainability innovations. Int. J. Tech. Manag. 2013, 63, 4-23. [CrossRef]

60. Clarke, A.; MacDonald, A. Outcomes to partners in multi-stakeholder cross-sector partnerships: A resource-based view. Bus. Soc. 2019, 58, 298-332. [CrossRef]

61. Bryson, J.M.; Crosby, B.C.; Middleton Stone, M. The design and implementation of cross-sector collaborations: Propositions from the literature. Public Adm. Rev. 2006, 66, 44-55. [CrossRef]

62. Van Tulder, R.; Seitanidi, M.M.; Crane, A.; Brammer, S. Enhancing the impact of cross-sector partnerships. J. Bus. Ethics 2016, 135, 1-17. [CrossRef]

63. Crane, A. Exploring green alliances. J. Mark. Manag. 1998, 14, 559-579. [CrossRef]

64. Seitanidi, M.M. Adaptive responsibilities: Non-linear interactions across social sectors-Cases from cross sector social partnerships. Emerg. Complex. Org. J. 2008, 10, 51-64.

65. Skelcher, C.; Sullivan, H. Working across Boundaries-Collaboration in Public Services; Palgrave Macmillan: Basingstoke, UK, 2002.

66. Kanda, W.; Sakao, T.; Hjelm, O. Components of business concepts for the diffusion of large scaled environmental technology systems. J. Clean. Prod. 2016, 128, 156-167. [CrossRef]

67. Seitanidi, M.M.; Crane, A. Implementing CSR through partnerships: Understanding the selection, design and institutionalisation of nonprofit-business partnerships. J. Bus. Ethics 2009, 85, 413-429. [CrossRef]

68. Seitanidi, M.M.; Koufopoulos, D.N.; Palmer, P. Partnership formation for change: Indicators for transformative potential in cross sector social partnerships. J. Bus. Ethics 2010, 94, 139-161. [CrossRef] 
69. Selsky, J.W.; Parker, B. Cross-sector partnerships to address social issues: Challenges to theory and practice. J. Manag. 2005, 31, 849-873. [CrossRef]

70. Kale, P.; Singh, H. Managing strategic alliances: What do we know now, and where do we go from here? Acad. Manag. Perspect. 2009, 23, 45-62. [CrossRef]

71. Kumar, R. Managing ambiguity in strategic alliances. Calif. Manag. Rev. 2014, 56, 82-103. [CrossRef]

72. McDonald, S.; Young, S. Cross-sector collaboration shaping corporate social responsibility best practice within the mining industry. J. Clean. Prod. 2012, 37, 54-67. [CrossRef]

73. Barroso-Méndez, M.J.; Galera-Casquet, C.; Seitanidi, M.M.; Valero-Amaro, V. Cross-sector social partnership success: A process perspective on the role of relational factors. Eur. Manag. J. 2016, 34, 674-685. [CrossRef]

74. Christoffersen, J. A review of antecedents of international strategic alliance performance: Synthesized evidence and new directions for core constructs. Int. J. Manag. Rev. 2013, 15, 66-85. [CrossRef]

75. Teece, D. Business models and dynamic capabilities. Long Range Plan. 2018, 51, 40-49. [CrossRef]

76. Franco, M. Determining factors in the success of strategic alliances: An empirical study performed in Portuguese firms. Eur. J. Int. Manag. 2011, 5, 608-632. [CrossRef]

77. Abdi, M.; Aulakh, P.S. Locus of uncertainty and the relationship between contractual and relational governance in cross-border interfirm relationships. J. Manag. 2017, 43, 771-803. [CrossRef]

78. Cao, Z.; Lumineau, F. Revisiting the interplay between contractual and relational governance: A qualitative and meta-analytic investigation. J. Oper. Manag. 2015, 33, 15-42. [CrossRef]

79. Poppo, L.; Zhou, K.Z.; Zenger, T.R. Examining the conditional limits of relational governance: Specialized assets, performance ambiguity, and long-standing ties. J. Manag. Stud. 2008, 45, 1195-1216. [CrossRef]

80. Lee, Y.; Cavusgil,S.T. Enhancing alliance performance: The effects of contractual-based versus relational-based governance. J. Bus. Res. 2006, 59, 896-905. [CrossRef]

81. Zaheer, A.; Venkatraman, N. Relational governance as an interorganizational strategy: An empirical test of the role of trust in economic exchange. Strateg. Manag. J. 1995, 16, 373-392. [CrossRef]

82. Lin, N.; Cook, K.S.; Burt, R.S. (Eds.) Social Capital: Theory and Research; Transaction Publishers: Piscataway, NJ, USA, 2001.

83. $\mathrm{Mu}$, J.; Peng, G.; Love, E. Interfirm networks, social capital, and knowledge flow. J. Know. Manag. 2008, 12, 86-100. [CrossRef]

84. Ortiz, B.; Donate, M.J.; Guadamillas, F. Inter-organizational social capital as an antecedent of a firm's knowledge identification capability and external knowledge acquisition. J. Know. Manag. 2018, 22, 1332-1357. [CrossRef]

85. Galati, F.; Bigliardi, B. Redesigning the model of the initiation and evolution of inter-firm knowledge transfer in R\&D relationships. J. Know. Manag. 2019, 23, 2039-2066.

86. Liu, Y.; Li, Y.; Shi, L.H.; Liu, T. Knowledge transfer in buyer-supplier relationships: The role of transactional and relational governance mechanisms. J. Bus. Res. 2017, 78, 285-293. [CrossRef]

87. Eisenhardt, K.M. Building theories from case study research. Acad. Manag. Rev. 1989, 14, 532-550. [CrossRef]

88. Eisenhardt, K.M.; Graebner, M.E. Theory building from cases: Opportunities and challenges. Acad. Manag. J. 2007, 50, 25-32. [CrossRef]

89. Patton, M.Q. Qualitative Research E Evaluation Methods, 3rd ed.; SAGE: London, UK, 2002.

90. Miles, M.B.; Huberman, A.M.; Saldaña, J. Qualitative Data Analysis: A Methods Sourcebook; SAGE: London, UK, 2014.

91. Maykut, R.; Morehouse, R. Beginning Qualitative Research: A Philosophical and Practical Guide; The Falmer Press: London, UK, 1994.

92. Creswell, J.W. Research Design: Qualitative, Quantitative, and Mixed Methods Approaches; SAGE: London, UK, 2003.

(C) 2020 by the authors. Licensee MDPI, Basel, Switzerland. This article is an open access article distributed under the terms and conditions of the Creative Commons Attribution (CC BY) license (http://creativecommons.org/licenses/by/4.0/). 